\title{
Evaluation of fluorine level in different tea cultivars for Sichuan dark tea production
}

\author{
Zou Yao1, a, Tan Liqiang1, b, Tang Qian ${ }^{1, c^{*}}$, Li Huili"1, d \\ ${ }^{1}$ Department of Tea Science, College of Horticulture, Sichuan Agricultural University, Chengdu \\ 611130, China \\ azouyao82@163.com, b617886140@qq.com, ctangqi2008@126.com, d2267624931@qq.com \\ ${ }^{*}$ Corresponding author. Zou Yao and Li Huili contributed equally to this work.
}

\section{Keywords: Fluorine; Tea cultivar; Sichuan dark tea}

\begin{abstract}
Tea plant (Camellia sinensis) could accumulate fluorine (F) in leaves efficiently. Fresh tea leaves are always regarded as the culprit of excess F in Sichuan dark tea (SDT). The present study evaluated $\mathrm{F}$ level in different tea cultivars and young shoots to select the appropriate production raw materials. Results showed that $\mathrm{F}$ level varied greatly among tea cultivars, from 65.9 to $821.6 \mathrm{mg} \mathrm{kg}^{-1}$ in the young shoots with five expanded leaves and increased with the age of young shoots. Young shoots with up to seven leaves of Zhongcha 108 or Fuding Dabaicha had the lower F level and could be used as the appropriate raw materials to produce Sichuan dark tea.
\end{abstract}

\section{Introduction}

Sichuan dark tea (SDT) is one of the most important dark teas in China [1]. For centuries, SDT has always been the life necessity to the minority ethnic groups living Tibet who has the diets mainly consist of red meat and milk products. For them, SDT is not only a beverage but also a folk medicine due to the significant activities of hypolipidemic and lifting greasy $[2,3]$, and is also a source of Vitamin C [4].

Sichuan dark tea is usually made from relatively old shoots of tea plant (Camellia sinensis), however, this plant just like $\mathrm{F}$ hyper-accumulator, high level of $\mathrm{F}$ is always discovered in its matured leaves [5,6]. Therefore, compared with other teas, the content of $F$ in SDT is usual over $700 \mathrm{mg} \cdot \mathrm{kg}^{-1}$ (dry weight, DW), sometimes even up to $1000 \mathrm{mg} \cdot \mathrm{kg}^{-1}$ [7]. Excessive consumption of SDT with high F level for a long time has been blamed as the culprit of "brick tea fluorosis" in northern Tibet [8]. In recent years, many strategies, such as chemical defluorination, physical defluorination, special cultivation techniques and breeding methods, have been performed to reduce F level in SDT $[9,10]$. However, on account of the security, defluorination effects and time costs, these strategies have seldom been used in SDT production to date.

In the present study, F levels of 55 tea cultivars planted in Sichuan were investigated.

\section{Materials and methods}

\subsection{Tea plants}

55 tea cultivars growing in the national tea breeding field in Ya'an city Sichuan province had been selected as experimental materials. Young shoots with one bud and five to ten leaves of experimental tea plants were harvested individually. A part of shoots were disassembled into stems and leaves for independent analyses. All the samples were cleaned with distilled water, then, dried at $60^{\circ} \mathrm{C}$ for $24 \mathrm{~h}$, crushed and passed through a 2-mm sieve. Five replicates for each sample.

In addition, we also collected the soil in the breeding field at the depths of $20-40 \mathrm{~cm}$ for $\mathrm{F}$ level and $\mathrm{PH}$ measurements.

\subsection{Chemical analysis}

Water-soluble F of samples were extracted with distilled water, and measured with F-ion selective 
electrode according to the national standard method of China [11]. Soil PH was detected by the agricultural standard method of China [12].

\subsection{Data analysis}

Descriptive statistics and significant difference test were performed with SPSS software 19.0 (SPSS Inc. USA). Histogram was generated by Origin 9.0 software (OriginLab Co., USA) and SPSS 19.0.

\section{Results and discussion}

\subsection{F level in different tea cultivars}

F level in young shoots with a bud and five expanded leaves of the tested tea plants varied greatly, the range of which up to 755.69 and the variation coefficient among the cultivars was 0.547 (table 1). F content of $85.45 \%$ tested plants was less than $300 \mathrm{mg} \cdot \mathrm{kg}^{-1}$ and $10.91 \%$ cultivars was less than $100 \mathrm{mg} \cdot \mathrm{kg}^{-1}$. Zhongcha 108 had the lowest F content $\left(65.93 \mathrm{mg} \cdot \mathrm{kg}^{-1}\right)$ while Taicha 12 had the highest F content $\left(821.58 \mathrm{mg} \cdot \mathrm{kg}^{-1}\right)$.

Table $1 \mathrm{~F}$ content in different tea cultivars

\begin{tabular}{|c|c|c|c|c|c|}
\hline Tea cultivars & $\begin{array}{l}\text { F content } \\
\left(\mathrm{mg} \cdot \mathrm{kg}^{-1}\right)\end{array}$ & Tea cultivars & $\begin{array}{l}\text { F content } \\
\left(\mathrm{mg} \cdot \mathrm{kg}^{-1}\right)\end{array}$ & Tea cultivars & $\begin{array}{l}\text { F content } \\
\left(\mathrm{mg} \cdot \mathrm{kg}^{-1}\right)\end{array}$ \\
\hline Zhongcha108 & $65.93 \pm 2.12$ & Qianmei419 & $166.13 \pm 2.16$ & Ying shuang & $267.22 \pm 3.69$ \\
\hline Fuding Dabaicha & $72.34 \pm 2.96$ & Emei Wenchun & $168.52 \pm 3.18$ & Shanchal & $270.03 \pm 2.54$ \\
\hline Xiangshanzao & $84.22 \pm 4.12$ & Mabianlv & $185.23 \pm 3.06$ & Nanjiang4 & $273.44 \pm 2.06$ \\
\hline Fuxuan 9 & $90.52 \pm 3.65$ & Echa8 & $185.81 \pm 2.26$ & Wuniuzao & $274.93 \pm 3.29$ \\
\hline Huangjingui & $90.81 \pm 2.48$ & Chuancha3 & $186.92 \pm 2.46$ & Longjing43 & $279.91 \pm 5.06$ \\
\hline Qianmei 419 & $96.04 \pm 3.78$ & Longjing Changye & $187.73 \pm 1.92$ & Yunkang10 & $285.34 \pm 2.73$ \\
\hline Cuifeng & $108.22 \pm 3.21$ & Zhongcha102 & $195.14 \pm 3.06$ & Pingyang Tezao & $288.54 \pm 3.66$ \\
\hline Juhuachun & $118.13 \pm 2.61$ & Jinguanyin & $209.01 \pm 1.65$ & Nanjiang Daye & $292.62 \pm 4.06$ \\
\hline Zhenong 117 & $118.11 \pm 4.65$ & Mingshan 213 & $214.62 \pm 3.66$ & Yunnan Daye & $293.83 \pm 2.49$ \\
\hline Qingxin1 & $128.84 \pm 5.62$ & Huangyazao & $216.63 \pm 2.39$ & Mingshanzao & $317.13 \pm 5.61$ \\
\hline Tieguanyin & $133.12 \pm 3.12$ & Qianmei303 & $219.86 \pm 3.12$ & Mingshan Tezao & $329.93 \pm 2.12$ \\
\hline Juhuaxiang & $133.24 \pm 3.52$ & Chuanmu217 & $219.80 \pm 2.67$ & Mengshan11 & $336.03 \pm 2.64$ \\
\hline Zaofengchun & $136.23 \pm 4.03$ & Zhongcha302 & $222.83 \pm 4.03$ & Chunbolv & $349.21 \pm 3.54$ \\
\hline Hongyan2 & $141.20 \pm 4.12$ & Huangye Shuixian & $235.41 \pm 1.98$ & Huangjinya & $371.32 \pm 4.19$ \\
\hline Meizhan & $147.14 \pm 5.21$ & Chuancha2 & $240.92 \pm 2.31$ & Mingshan131 & $383.21 \pm 4.44$ \\
\hline Echa 5 & $148.90 \pm 4.23$ & Sichuan Qunti & $241.61 \pm 4.22$ & Jianhe Xiangcha & $519.03 \pm 4.65$ \\
\hline Huangyezao & $153.0 \pm 3.68$ & Zhenong113 & $254.74 \pm 3.21$ & Taicha12 & $821.62 \pm 6.51$ \\
\hline Hongyan 12 & $154.63 \pm 2.74$ & Yuanxiaozao & $261.23 \pm 1.29$ & & \\
\hline Chuanmu28 & $158.54 \pm 3.63$ & Fuyun 6 & $261.62 \pm 2.34$ & & \\
\hline
\end{tabular}

Values are expressed as mean \pm standard deviation of three replicates. F content and $\mathrm{PH}$ of soil in sampling location were $0.29-0.33 \mathrm{mg} \cdot \mathrm{kg}^{-1}$ and $5.12-5.35$ respectively; the variation coefficient of $\mathrm{F}$ content among the cultivars was 0.547 .

\subsection{F level in different young shoots of Zhongcha 108 and Fuding Dabaicha}

Tea cultivars with the lower F level (Zhongcha108 and Fuding dabaicha) were selected as materials to investigate $F$ content in young shoots of different maturity. The result showed that $F$ level increased with the maturity of tea shoots. F content of all the shoots of Zhongcha 108 and the shoots with a bud and five to eight leaves of Fuding Dabaicha were less than $300 \mathrm{mg} \cdot \mathrm{kg}^{-1}$, especially, in the shoots with up to seven leaves of both cultivars, this value was less than $150 \mathrm{mg} \cdot \mathrm{kg}^{-1}$ (Fig.1). 


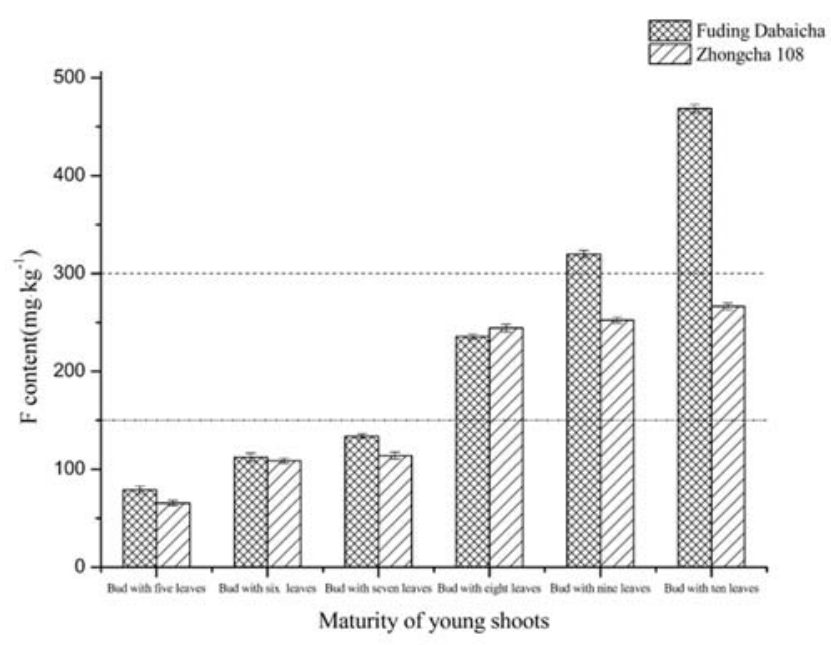

Fig.1 F content in different young shoots of Zhongcha 108 and Fuding Dabaicha.

\subsection{F level in different parts of Zhongcha 108 and Fuding Dabaicha young shoots}

The leaves and stems of Zhongcha 108 and Fuding Dabaicha young shoots were separated, and no matter in which cultivars, F was concentrated in leaves, the values varied from 152.31 to 411.38 $\mathrm{mg} \cdot \mathrm{kg}^{-1}$ and increased with the age of leaves, especially, in the leaves that older than $3^{\text {rd }}$ leaf of Fuding dabaicha and $4^{\text {th }}$ leaf of Zhongcha 108 this value was higher than $300 \mathrm{mg} \cdot \mathrm{kg}^{-1}$, but in stems, regardless of the position, F content was less than $10 \mathrm{mg} \cdot \mathrm{kg}^{-1}$ in both cultivars(Fig.2).

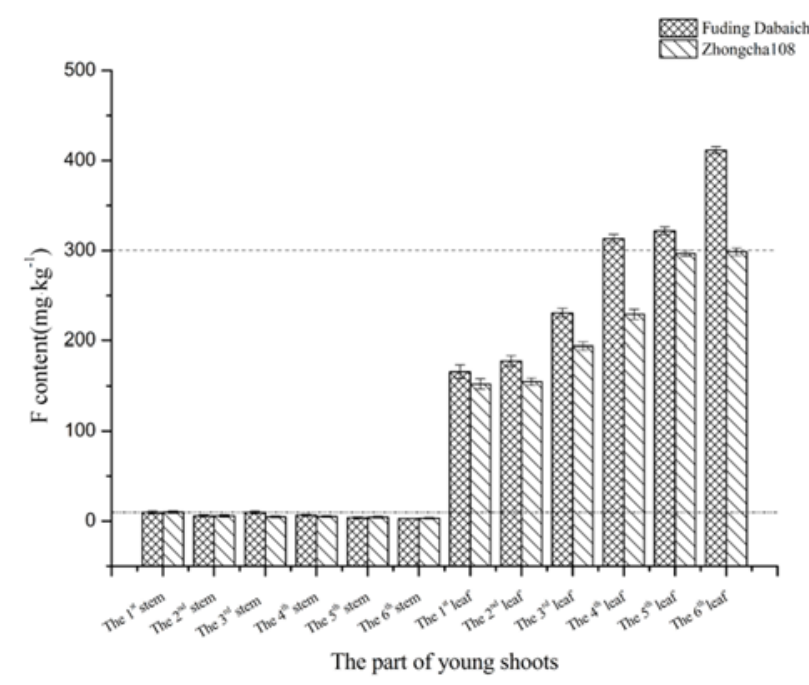

Fig. 2 F content in different positions of Zhongcha 108 and Fuding Dabaicha young shoots

\section{Conclusion}

F level varied greatly among tea cultivars and increased with the age of young shoots, it mainly accumulated in leaves, scarcely in stems. Appropriate young shoot from the right cultivar was the key point to control F level in SDT. It was suggested that tea shoots with up to seven expanded leaves of Zhongcha 108 and Fuding Dabaicha were the appropriate production raw materials for Sichuan dark tea.

\section{Acknowledgements}

This work was supported by Education Department Project of Sichuan Province, China (15ZA0017). 


\section{References}

[1] C.G. Li and G.D. Li: Tibetan Tea (Sichuan Nationalities Publishing House, China 2007)

[2] B. Jiang: Study on inhibitory effects of Sichuan brick tea on fatty acid synthase(Master thesis: Sichuan Agricultural University, China 2007)

[3] T. Xu: Studies on the hypoglycemic activity and optimum extraction of theabrownine from Sichuan brick tea(Master thesis: Sichuan Agricultural University, China 2010)

[4] W. Xu: Identification of fungal colonization of Sichuan Kang zhuan tea during pile-fermentation (Master thesis: Sichuan Agricultural University, China 2010)

[5] J.Jolanta and B. Maria: Food Analytical Methods Vol. 6(2013), p.1090.

[6] H.M. Cai, C.Y. Peng, C.L. Li, W. Gao, R. Hou and X. Wan: Scientia Agricultura Sinica Vol. 46(2013), p. 1668.

[7] W.S. Shu, Z.Q. Zhang, C.Y. Lan and M.H. Wong: Chemosphere Vol. 52(2003), p. 1475.

[8] J. Cao, Y. Zhao and J.W. Liu: Journal of Fluorine Chemistry Vol. 106(2000), p. 93.

[9] J.Y. Ruan, L.F. Ma, Y.Z. Shi and W. Han: Annals of Botany Vol. 93(2004), p. 97.

[10] X.P. Luo: Study on the technologies and mechanisms of reducing fluorine in Sichuan brick tea ( Master thesis: Sichuan Agricultural University, China 2007)

[11] AQSIQ and National Standardization Administration Committee of China, China National Standard GB/T21728-2008. (2008)

[12] Ministry of Agriculture of China, Ministry of Agriculture of China Standard NY/T 1377-2007. (2007) 